\title{
IMPROVED DYNAMIC RESPONSE OF PFC-SEPIC CONVERTER BASED ON INDUCTION HEATER USING FOPID CONTROLLED SYSTEM
}

\author{
Muthu Periasamy ${ }^{\# 1}$, Chandrahasan Umayal ${ }^{2}$ \\ ${ }^{\#}$ Research Scholar, ${ }^{*}$ Associate Professor \\ \# School of Electrical Engineering, VIT University, Chennai, India \\ * School of Electrical Engineering, VIT University, Chennai, India \\ ${ }^{\#}$ E-Mail: muthuvit2007@gmail.com \\ *E-Mail: umayal.c@vit.ac.in
}

\begin{abstract}
This work deals with the power factor corrected single ended primary inductor converter (PFC-SEPIC) based voltage fed closed loop full bridge series resonant induction heating system for household induction heating applications. The output voltage of the front end PFC-SEPIC converter fed series resonant inverter governs the controllers which may be PI controller or FOPID controllers. The analysis and comparison of time responses are presented in this paper. PFC-SEPIC converter is used to improve the output power and the THD of source side current are compared for PI and FOPID controllers. PFC-SEPIC converter maintains improved current and voltage at unity power factor through the input mains. The SEPIC converter based voltage fed full bridge series resonant inverter (VFFBSRI) converts the voltage at a frequency of $10 \mathrm{kHz}$ to a level suitable for household induction heating. A $1 \mathrm{~kW}$ SEPIC converter based VFFBSRI with RLC load is designed and simulated using MATLAB/ Simulink and hardware is fabricated.
\end{abstract}

Keywords - SEPIC Converter; Power Factor Correction (PFC); Induction Heating (IH); VFFBSRI; PI\& fractional order PID controller;

\section{INTRODUCTION}

Induction heating is employed in many domestic and industrial applications due to its various advantages like safeness, cleanness, adaptability and non-contact compared with the other classical methods of heating. Electrical energy supplied from the utility AC supply to the coil is transformed to thermal energy in the work piece by inducing eddy currents at the work piece surface over the electromagnetic field, in the absence of any physical electrical connection to the work piece. At the work piece surface this induced current intensity is maximal and lowers as the center is approached. This is the function of the ratio of thickness/skin depth. The skin depth and size of the work piece plays a crucial role in the operating frequency selection. A larger percentage of the entire power is exhausted as the ratio increases along the exterior surface and this aspect is termed as skin depth.

The various topologies which are commonly used for induction heating applications are half bridge, full bridge and single switched zero voltage switching (ZVS) or zero current switching (ZCS) inverter. The comparative analysis of the above said topologies were discussed earlier [1] by considering similar specifications with several factors. In general, resonant based high frequency inverters are always preferred in induction heating applications in order to have less switching losses and high power output. Various modulation schemes were developed to have high heating function amidst proper voltage control. In PFC-SEPIC converter based induction heating the converter regulates the voltage at the DC link to a much smaller value compared with the traditional PFC boost converter [2] despite improving the quality of power at inputs. The stress on switches is guarded by making the SEPIC converter to operate in continuous inductor current mode (CICM). Various titles related with modeling and design of domestic induction appliances are analyzed and compiled [3] focusing on their future trends. The topics include topologies of the inverter, modulation techniques, implementation on digital controllers and design of inductors. The approach, theory and the conceptions of induction heating were discussed way back in 1973 [4]. The features of induction heating are well advanced compared with the traditional range and has remarkable thermal response, safeness and comfort. These features are achievable only because of electromagnetic induction which allows the vessel to get heated directly. Analysis of performance of free biomass induction heating system with SEPIC converter and without the SEPIC converter was dealt [5] to accomplish a better power factor and decreased total harmonic distortion. This was done by proposing a novel single switch AC-DC PFC topology. It is convinced that Induction heating technology is a promising one both at present and in future [6] by investigating and validating various 
techniques involved in induction heating systems. To supply medium and high frequency power signals to the inductor a uniquely designed output resonant circuit is used along with an exclusive inverter circuit. The $10-\mathrm{kW}$ dual frequency resonant circuit which is capable of operation at $10 \mathrm{kHz}$ and $100 \mathrm{kHz}$ make use of two technologies namely silicon (Si) and silicon carbide (SiC). Efficiency and loss in power of inverter using both technologies are compared and listed [7]. Research on the strength of the current control strategy [8] was presented in which a resonant control tracks the correct reference for current. Methods for tuning the controllers were also discussed in detail during very low switching/ sampling frequencies. Home appliances supplied by a DC based nanogrids form the major portion in recent studies on home appliances. Induction heating was considered [9] as an example for such a study. Here detailed designing which included power converters, inductor systems were taken into consideration. Implementation of hardware was also done on performance of converters. An innovative soft-switching high frequency resonant inverter for the application of induction heating was detailed [10]. This uses a current phasor control which adjusts the phase shift angle among the couple of half-bridge inverter units. By this method induction heating load resonant current is supervised and controlled at typical intervals using soft switching. Along this efficiency is also improved by dual mode power regulation method. A different model of a zero voltage soft switching, working at normal frequency utility AC mains to high frequency AC resonant power converter used in induction heating appliances is discussed [11]. This converter manages the conversion of frequency in the absence of any diode bridge rectifier along with power factor correction. Analysis and design of a novel ac-ac resonant converter for induction heating applications constituting half bridge resonant converters was discussed [12]. This converter is capable of functioning with zero voltage switching while the switch is ON and OFF. The voltage at the output is doubled with this network thereby reducing the load current. Above all induction-heating appliances need distinct features like increased power levels at the output in a smaller enclosure, increased operating temperature, and huge variation in load and cost effective. A proposal was given [13] with a lesser number of components, cheaper and reliable which make use of a direct ac-ac converter. This topology has soft switching during both turn-ON and turn-OFF thereby improving efficiency. A straightforward power-control scheme was discussed [14] for a consistent-frequency class-D inverter which has variable duty cycle. This is convenient to heat an induction heating appliance. This method has a vast range of power regulation as well as easy control of output power. Four different topologies of inverters for induction cookers were dealt with [15-16] and their performance with respect to stress on the device, control of frequency, efficiency were compared. A single switch silicon carbide JFET resonant inverter which is normally ON is used in an induction heating appliance [17-18] and a comparison is made with Si IGBTs and results are discussed.

An innovative driving techniques for was proposed [19] for a one witch zero voltage switching topology, which was claimed to have reduced crisis of peak currents. Usage of Litz-wire planar windings, which has frequency-dependent resistance, in induction appliances, is discussed [20]. A comparative study has been done with various wires for inductors. Since induction appliance with fluctuating induction loads is a threat to designing a resonant converter with more efficiency [21] a variable snubber topology has been proposed. To improvise efficiency over a broader power output, [22] a half-bridge LLCC Resonant inverter functioning in two different operating modes is proposed. This makes the system cheaper in terms of cost and effective. A multiple output, boost resonant AC-AC converter to improve efficiency and have reduced count of components for multiple-load systems [23] have been PI controlled system investigated. A novel voltage fed quasi load resonant inverter with variable power and constant frequency [24] was developed Fractional Order PID Controlled system for induction heating appliances. This soft switching inverter which uses IGBTs is found to be more applicable for a multiple burner induction heating systems. Another prototype is also presented by using the dual pulse modulation technique [25] performance of sepic converter has been implemented. This applies a sub scheme for regulating power to increase efficiency.

\section{PROPOSED PFC-SEPIC CONVERTER BASED IH}

This work deals with the PFC-SEPIC based voltage fed closed loop full bridge series resonant induction heating system for household induction heating applications. The output voltage of the front end PFC-SEPIC converter fed series resonant inverter governs the PI and FOPID controllers. PFC-SEPIC converter maintains improved current and voltage at unity power factor at the input mains. The SEPIC converter based voltage fed full bridge series resonant inverter (VFFBSRI) converts the voltage at a frequency of $10 \mathrm{kHz}$ to a level suitable for household induction heating.

Conventional Square wave (SW) modulation signifies large switching frequencies to supply low and medium power. To ensure good efficiency size of sink and fan have to be reduced. The main objective of this paper is to propose a modified control algorithm which improves efficiency while maintaining the same parameters with no hardware changes. To accomplish this asymmetrical and theoretical analysis of duty cycle modulation technique has been carried out. A different operating condition are applied to improve efficiency and to increase output. Finally, a comparison is made between simulation and hardware results in terms of efficiency. Fig.1 shows the block diagram for the induction heating system. 


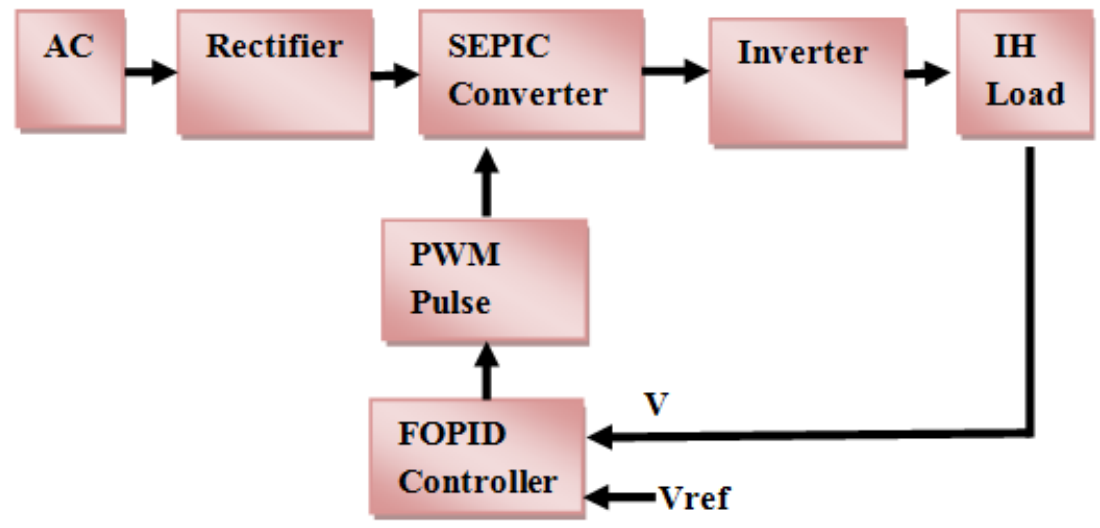

Fig.1. Block Diagram of the Induction Heating System.

The source supplies a rectifier which is followed by a DC-DC converter approach as the second stage converter. An inverter follows the DC-DC converter, which further supplies the induction heating system.

\section{MODES OF OPERATION FOR PFC-SEPIC CONVERTER}

Mode-1: In this mode of, the upper switch $\mathrm{S}$ is turned on and the energy stored in inductive coil is transferred to load by electromagnetic induction.

Mode-2: This mode of starts when the upper switch S is switched off. As soon as the upper switch is switched off, the resonant current free-wheels its energy through the body diode of lower switch d3, thus enabling it to turn on under ZVS condition.

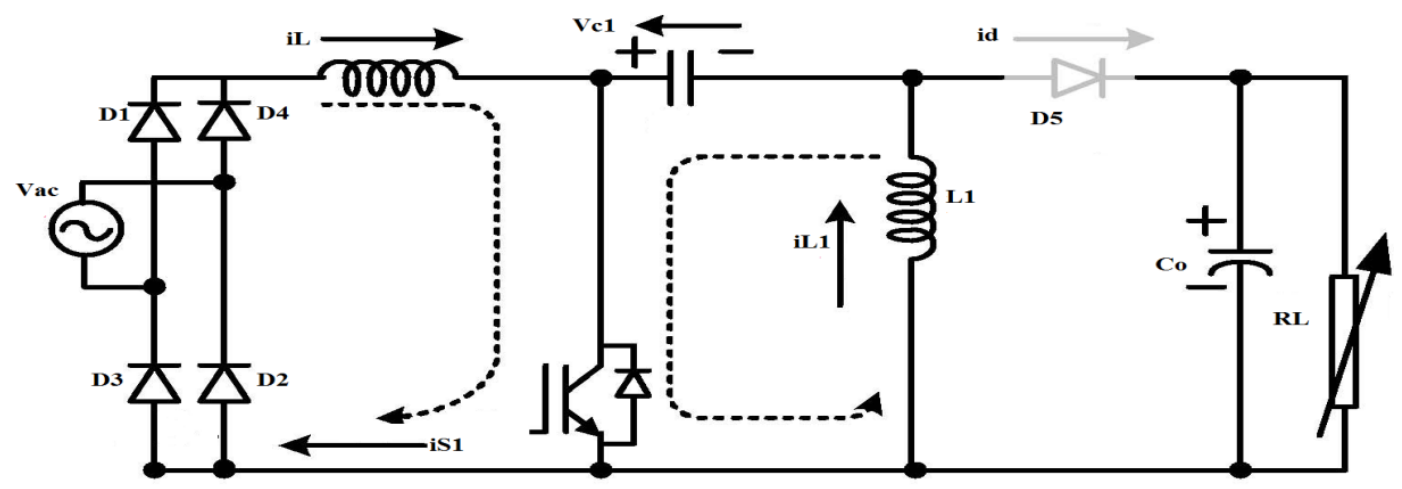

Fig.2. Mode1- Operation of PFC-SEPIC Converter during Ton.

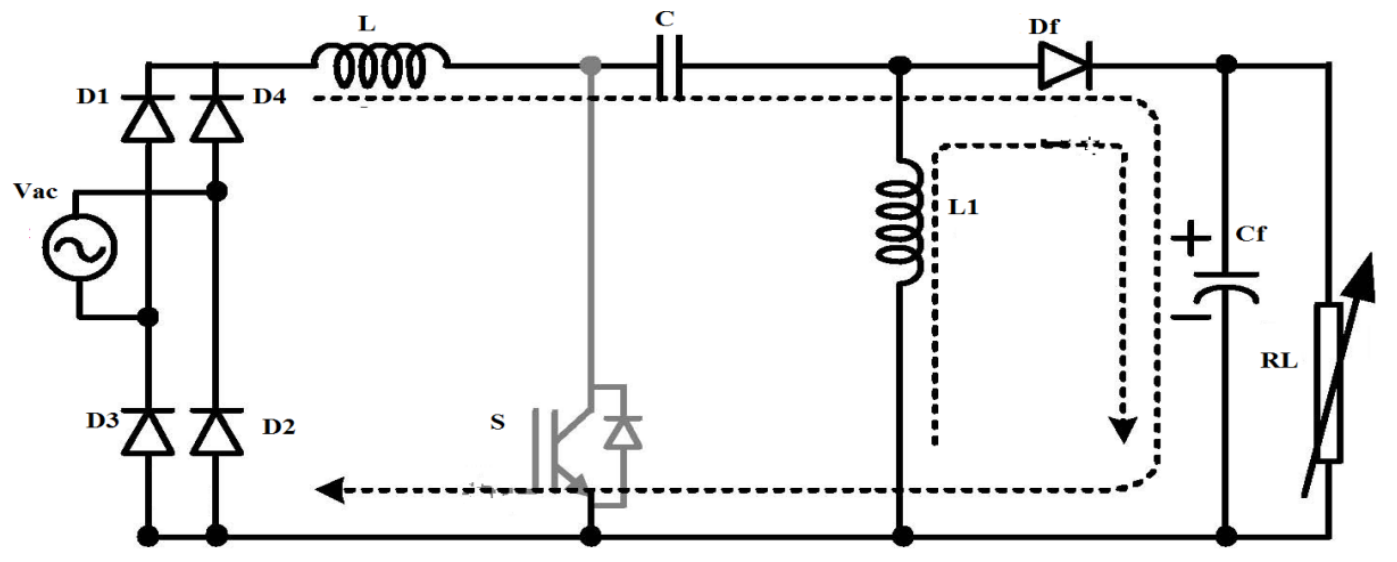

Fig.3. Mode2- Operation of PFC-SEPIC Converter during Toff.

\section{A. Design of PFC-SEPIC Converter}

The following equation as designed duty cycle ratio of $\mathrm{D}_{(\mathrm{t})}$. The inductor and filter capacitor as L, L1, C and SEPIC output capacitor voltage as $\mathrm{C}_{\mathrm{s} 0}$.

$$
D_{(t)}=\frac{V_{s o}}{V_{s o}+V_{\text {in }(t)}}
$$




$$
\begin{gathered}
\mathrm{D}_{(\max )}=\frac{\mathrm{V}_{\text {so }}}{\mathrm{V}_{\text {so }}+\sqrt{2} * \mathrm{~V}_{\text {in }}} \\
\Delta \mathrm{I}=\frac{\sqrt{2} * 35 \% * \mathrm{P}_{\mathrm{O}}}{\mathrm{D} * \mathrm{~V}_{\text {inmin }}} \\
\mathrm{L}=\mathrm{L}_{1}=\frac{\sqrt{2} * \mathrm{~V}_{\text {inmin }} * \mathrm{D}_{\text {min }}}{\Delta \mathrm{I}} \\
\mathrm{C}=\frac{\mathrm{V}_{\mathrm{O}}}{\mathrm{R} * \mathrm{f}_{\mathrm{s}} * \Delta \mathrm{V}_{\mathrm{c}}} \\
\mathrm{C}_{\mathrm{s} 0}=\frac{\mathrm{P}_{\mathrm{O}}}{2 * \pi * \mathrm{f}_{\mathrm{L}} * \mathrm{Vso} \Delta \mathrm{V}_{\mathrm{b}}}
\end{gathered}
$$

\section{MODES OF OPERATION FOR VFFBSRI SYSTEM}

Mode-1: In this stage, the upper switch S1and S2 is turned on and the energy flows from source to the inductive coil is transferred to load by electromagnetic induction.

Mode-2: In this stage, energy in $\mathrm{L}$ is returned to $\mathrm{d} 3$ and $\mathrm{d} 4$ to the source.

Mode-3: In this stage, the upper switch S3and S4 is turned on and the energy flows from source to the inductive coil is transferred to load by electromagnetic induction.

Mode-4: In this stage, energy in $\mathrm{L}$ is returned to $\mathrm{d} 1$ and $\mathrm{d} 2$ to the source.
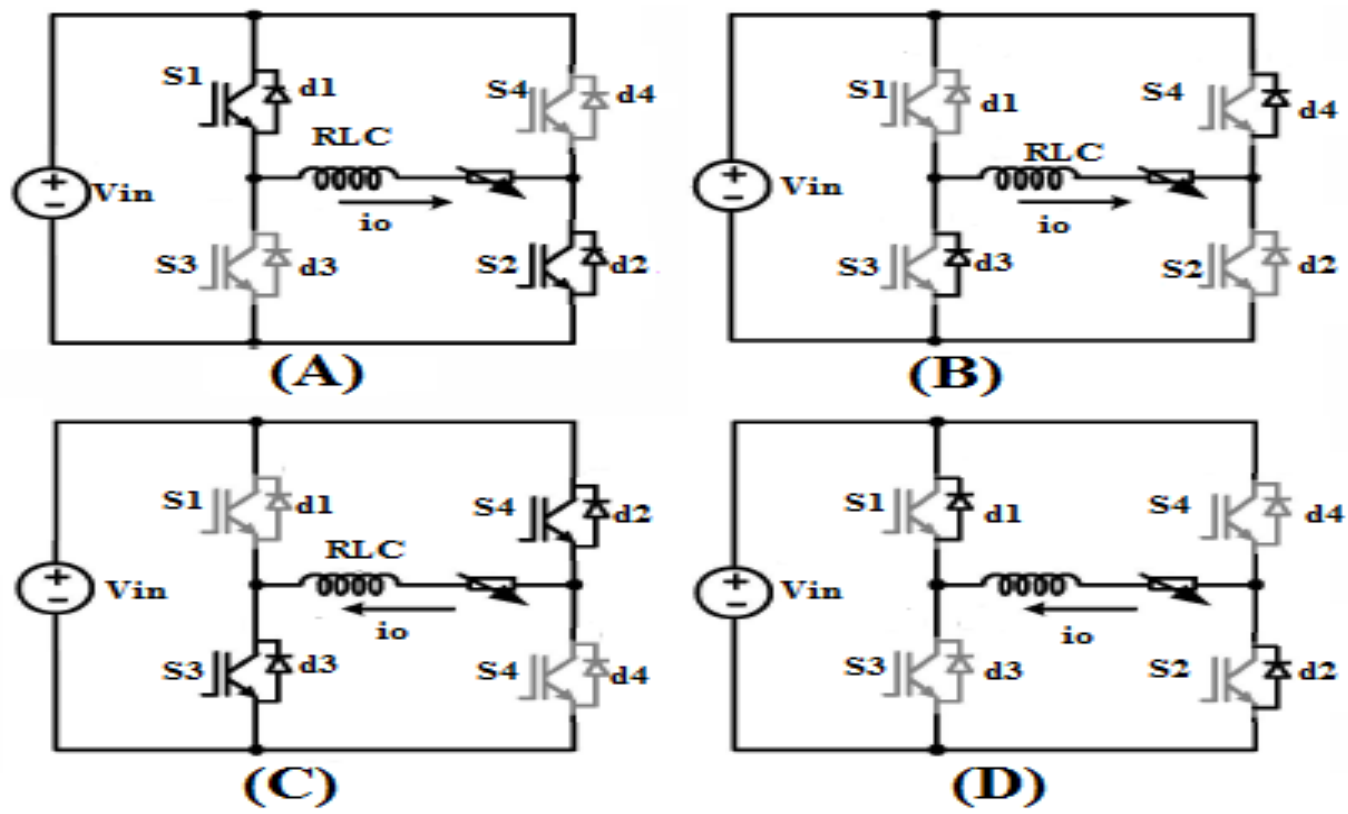

Fig. 4. Operating Modes of VFFBSRI-IH DC-AC Inverter

\section{A. Design of VFFBSRI Converter}

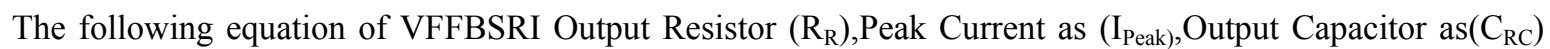
and Output Inductor as $\left(\mathrm{L}_{\mathrm{RL}}\right)$

$$
\begin{gathered}
\mathrm{R}_{\mathrm{R}}=\frac{2 \mathrm{Vso}^{2} \operatorname{Cos}^{2} \phi}{\pi^{2} \mathrm{P}_{0}} \\
\mathrm{I}_{\text {Peak }}=\frac{2 \pi \mathrm{P}_{0}}{2 \pi \mathrm{V}_{\mathrm{s} 0}} \\
\mathrm{C}_{\mathrm{R}}=\frac{\mathrm{I}_{\text {peak }}}{2 \pi \mathrm{f}_{\mathrm{r}} \mathrm{V}_{\mathrm{s} 0}} \\
\mathrm{~L}_{\mathrm{RL}}=\frac{1}{\left(2 \pi \mathrm{f}_{\mathrm{r}}\right)^{2} \mathrm{C}_{\mathrm{RC}}} \\
\text { V. SIMULATION RESULTS AND DISCUSSION }
\end{gathered}
$$

\section{SIMULATION RESULTS AND DISCUSSION}

\subsection{SEPIC with PI controller}

Simulink model of the SEPIC converter based voltage fed full bridge series resonant inverter (VFFBSRI) induction heating system with closed loop PI controller is shown in Fig.5. Input voltage and current is shown in Fig. 6. The source current THD is shown in Fig. 7. It shows the THD is $4.98 \%$. Output voltage of SEPIC converter is shown in Fig.8. The full bridge inverter output voltage \& current is shown in Fig.9 and Fig10. Output power of induction heating system is shown in Fig. 11. 


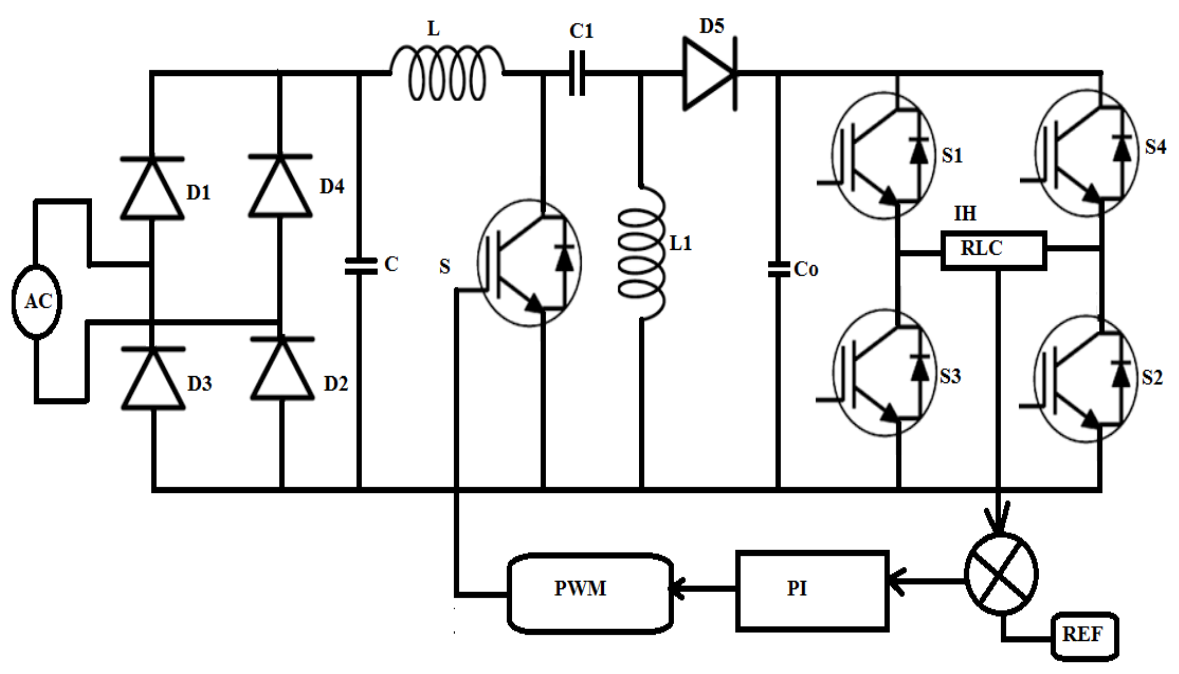

Fig.5. Circuit Diagram of SEPIC with VFFBSRI Closed Loop PI Controller Induction Heating System.

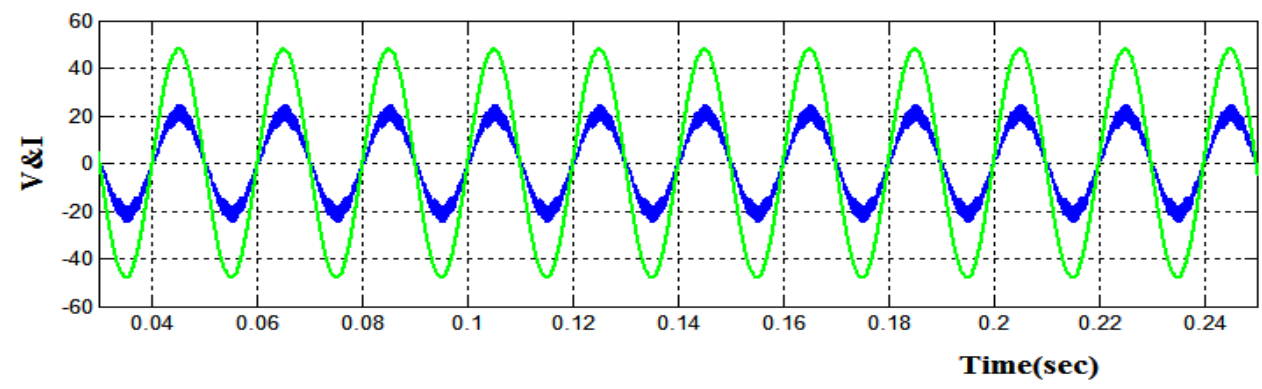

Fig. 6. Input Voltage and Current.

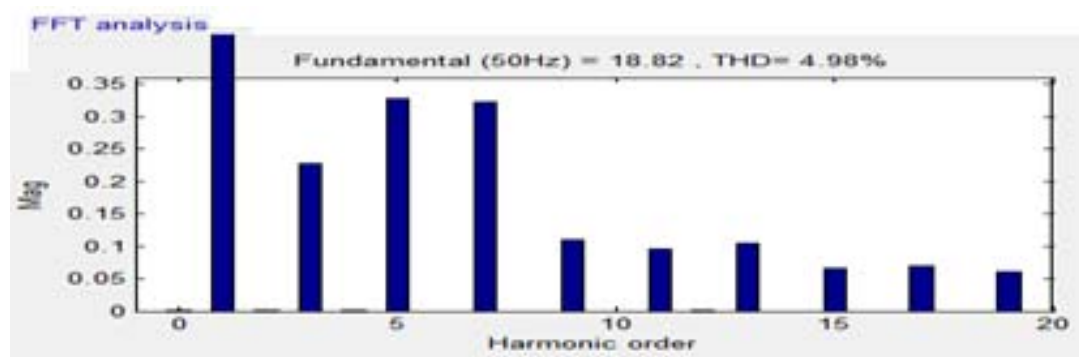

Fig.7. THD Analysis of Input Current of SEPIC Converter with PI controller.

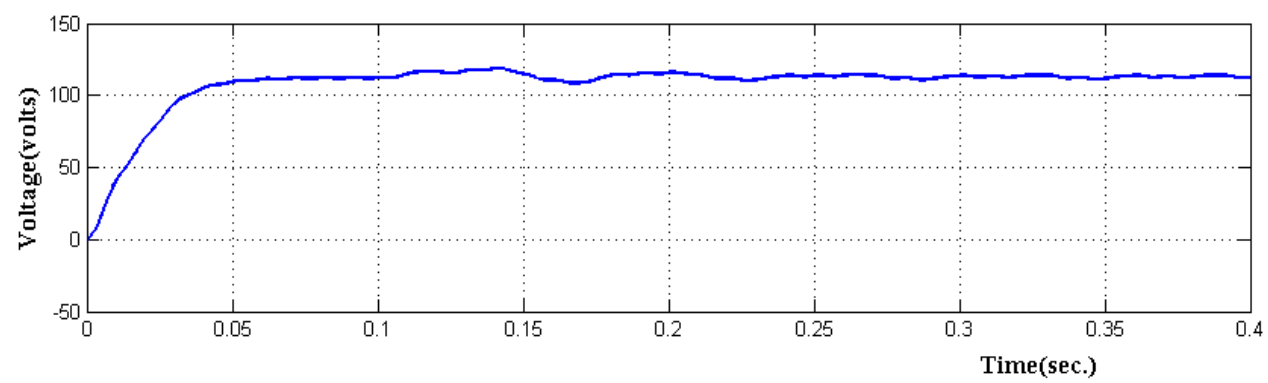

Fig.8. Output Voltage of SEPIC Converter. 


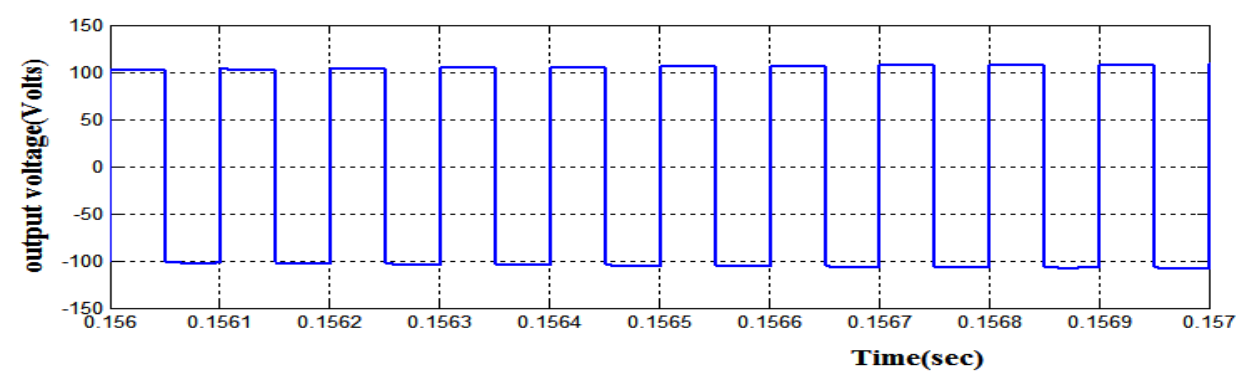

Fig. 9. Output Voltage of Inverter.

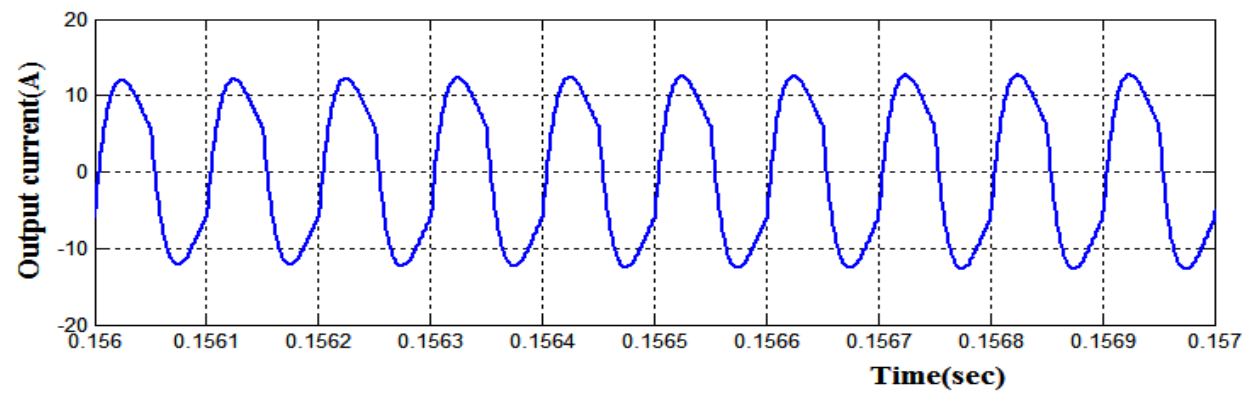

Fig.10. Output Current of Inverter.

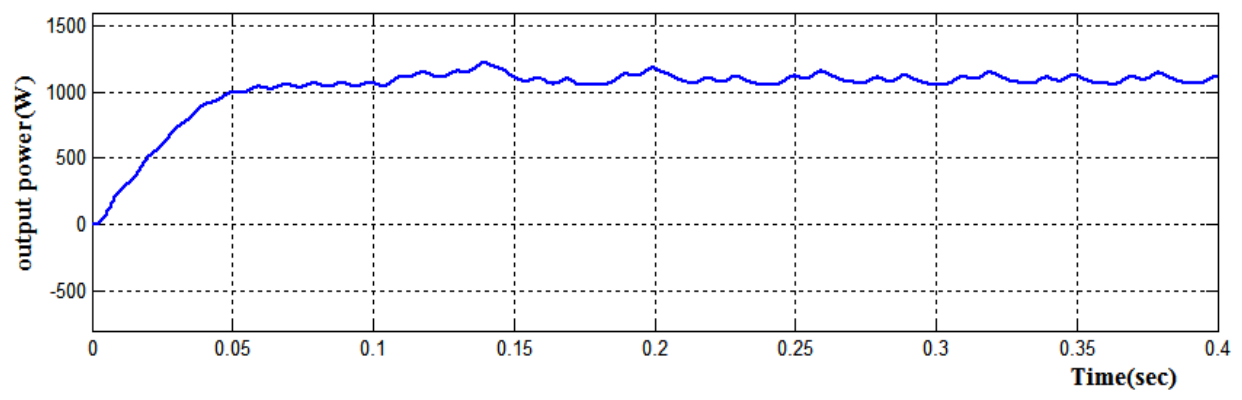

Fig.11. Output Power of Induction Heating System.

\subsection{SEPIC with FOPID controller}

Simulink model of SEPIC with VFFBSRI induction heating closed loop FOPID controller system is shown in Fig.12. Input voltage and current is shown in Fig. 13. The source current THD is shown in Fig. 14. Output voltage of SEPIC converter is shown in Fig.15. The full bridge inverter output voltage \& current is shown in Fig. 16-17. Output power of induction heating system is shown in Fig .18.

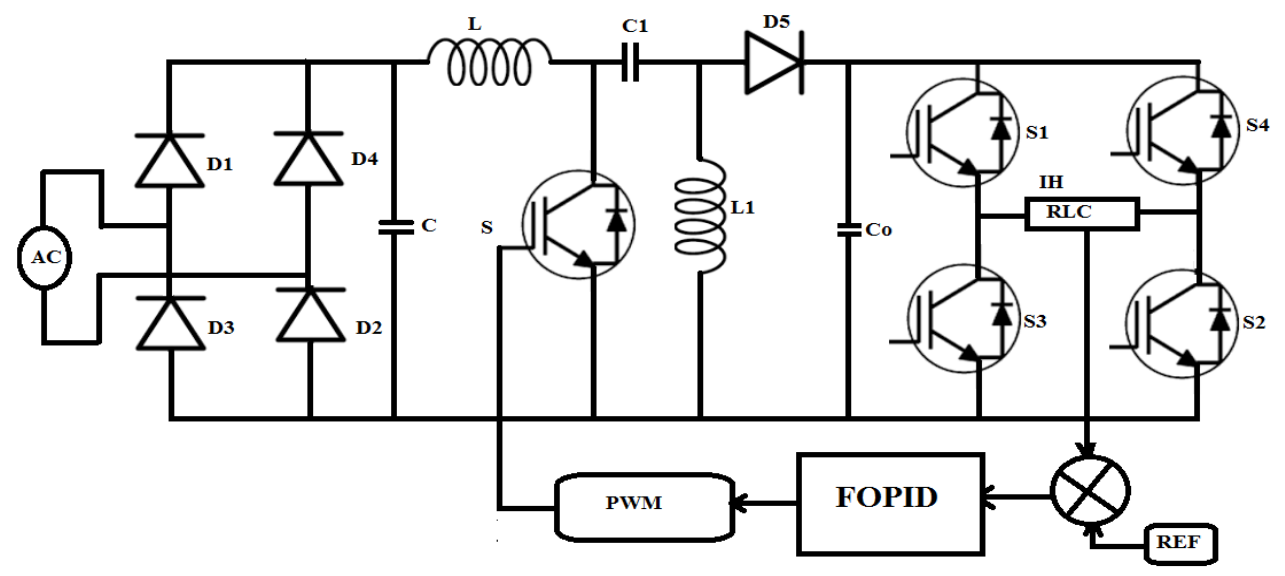

Fig. 12. Circuit Diagram for SEPIC with VFFBSRI Closed Loop FOPID Controller Induction Heating System. 


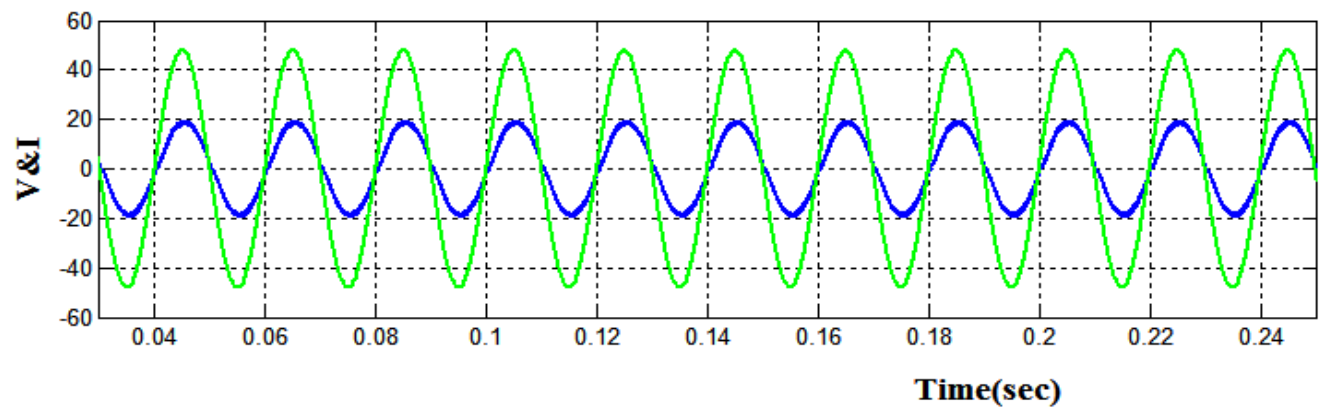

Fig.13. Input Voltage and Current.

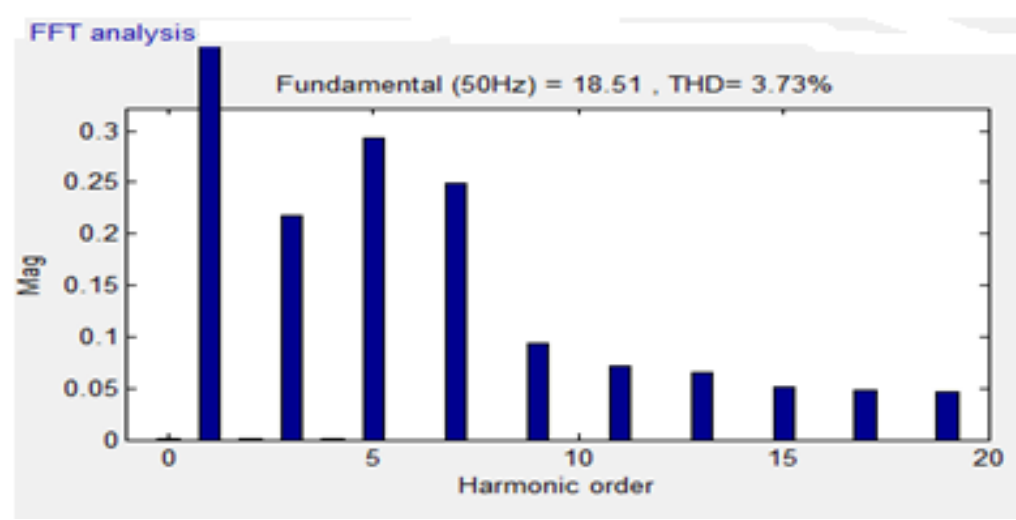

Fig. 14. THD Analysis of Input Current of SEPIC Converter with FOPID controller.

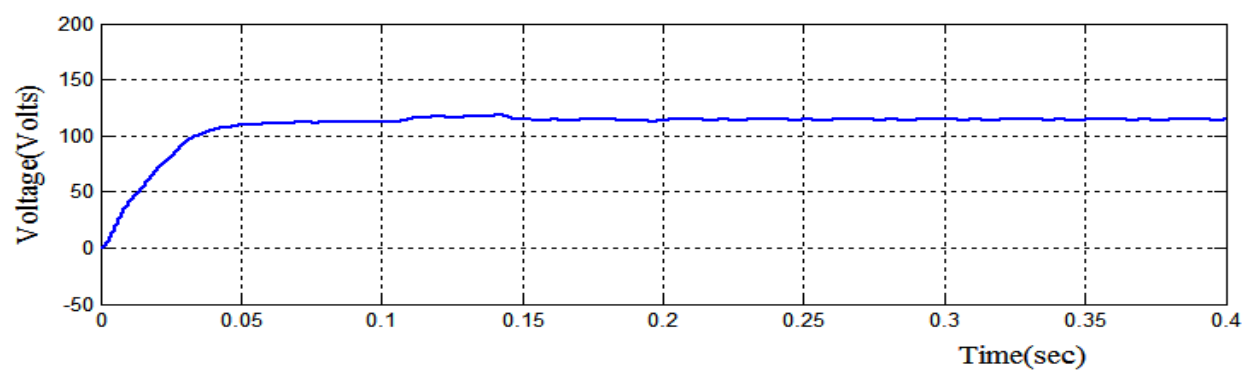

Fig. 15. Output Voltage of SEPIC Converter.

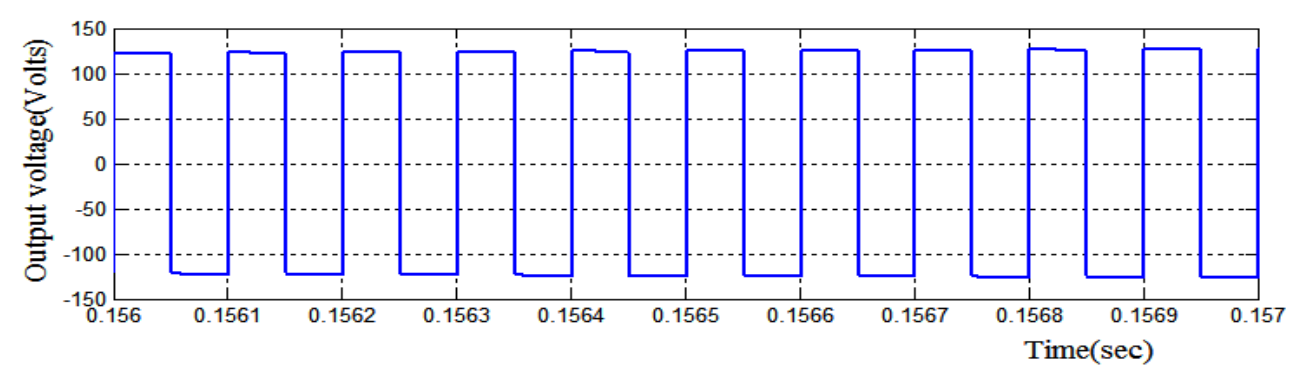

Fig. 16. Output Voltage of Inverter. 


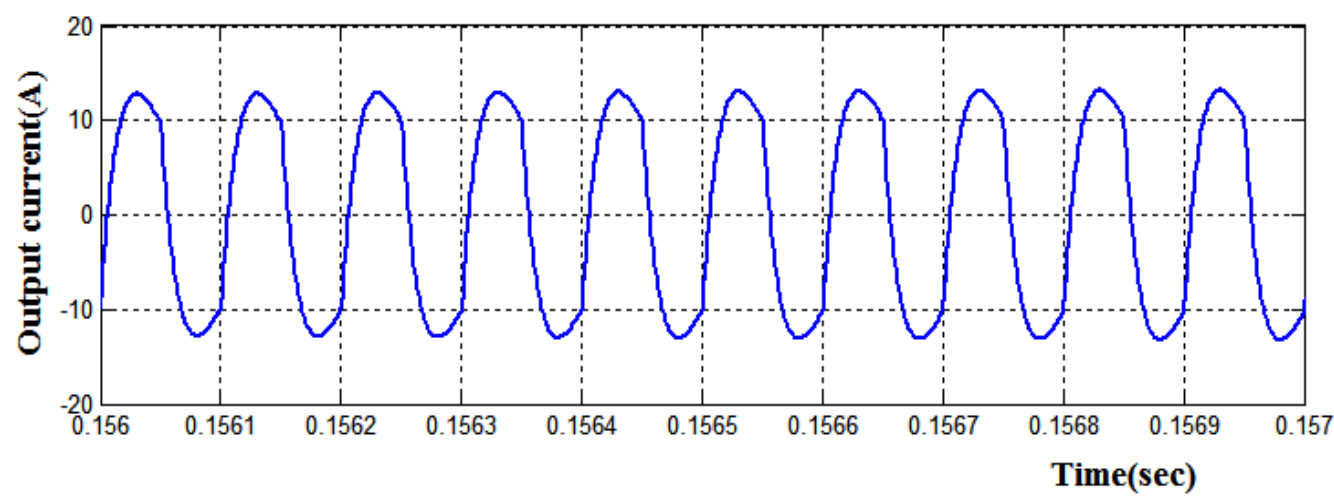

Fig. 17. Output Current of Inverter

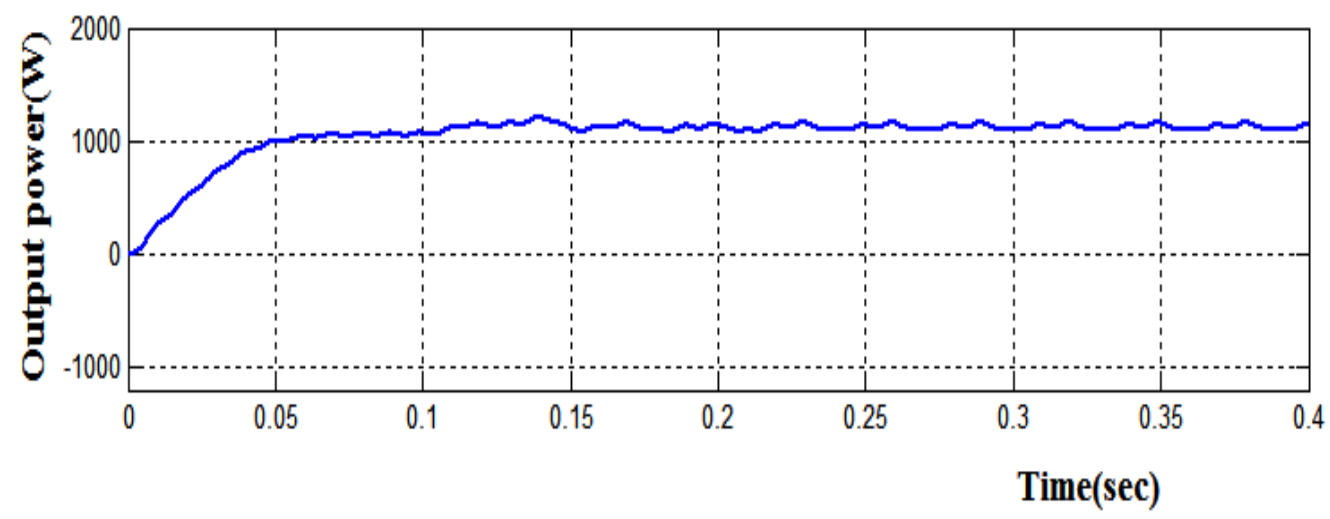

Fig.18. Output Power of Induction Heating System.

Table I. Comparison of Time Domain Parameters

\begin{tabular}{|l|c|c|c|c|c|}
\hline $\begin{array}{l}\text { Types of } \\
\text { Controller }\end{array}$ & Rise time (s) & Peak time (s) & Settling time (s) & $\begin{array}{c}\text { Steady state } \\
\text { error (v) }\end{array}$ & THD \\
\hline PI & 0.12 & 0.24 & 0.14 & 3.8 & $4.98 \%$ \\
\hline FOPID & 0.11 & 0.15 & 0.12 & 1.8 & $3.73 \%$ \\
\hline
\end{tabular}

Table 1 displays the comparison of time domain parameters and Table 2 displays the specifications used in simulating the system for PFC-SEPIC based voltage fed closed loop full bridge series resonant induction heating system for household induction heating applications with PI and FOPID controllers.

\section{EXPERIMENTAL RESULTS}

The hardware setup of the prototype whose input voltage is $48 \mathrm{~V}$, output voltage is $110 \mathrm{~V}$, has output power of $1 \mathrm{~kW}$ and switching frequency of $10 \mathrm{kHz}$. Hardware setup of SEPIC with VFFBSRI induction heating system is shown in Fig. 19. The hardware of SEPIC with VFFBSRI system is fabricated and tested in laboratory. The hardware consists of control board, SEPIC converter board \& VFFBSRI board. The pulses are generated using PIC 16F84A. They are amplified using driver IC 2110. Input voltage \& current of the system without controller is shown in Fig. 20. Fig. 21 shows the system with controller. Output voltage of SEPIC converter is shown in Fig.22. Output voltage of the inverter is shown in Fig. 23. Output current of the inverter is shown in Fig. 24. 


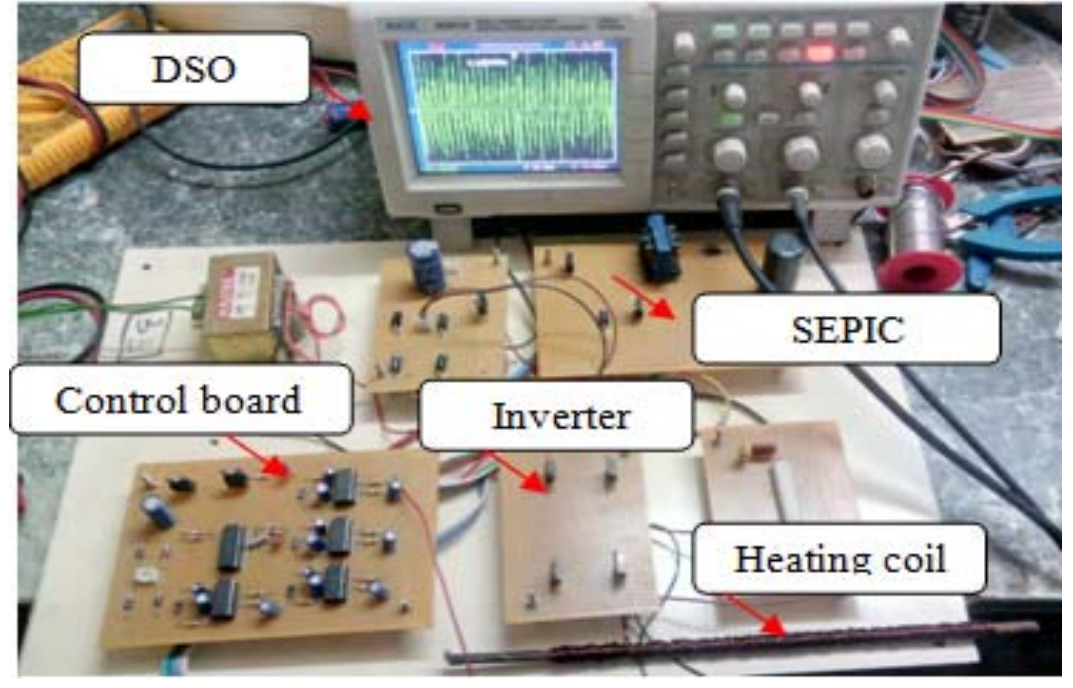

Fig. 19. Hardware Setup of the Prototype System.

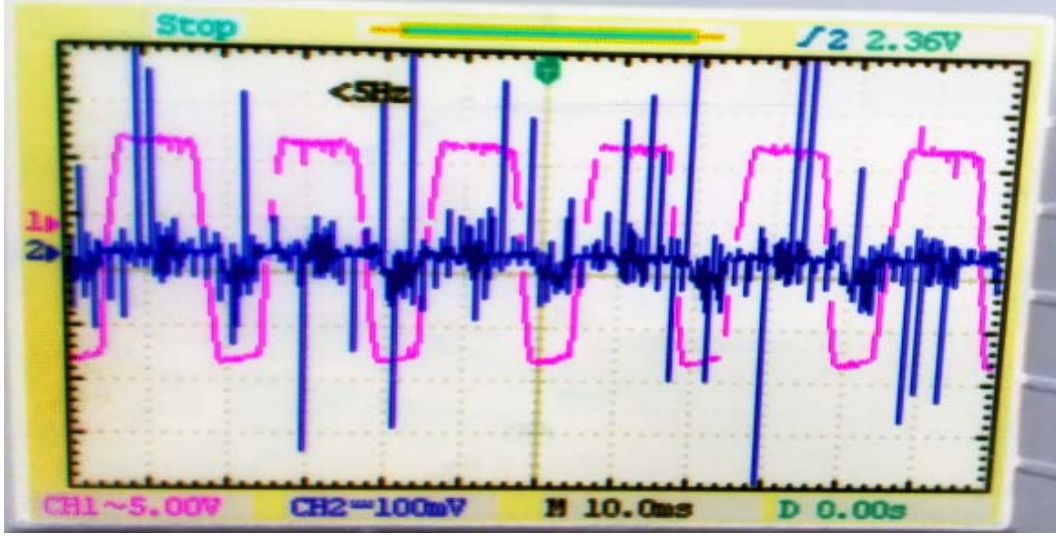

Fig. 20. Input Voltage and Current of the system without controller.

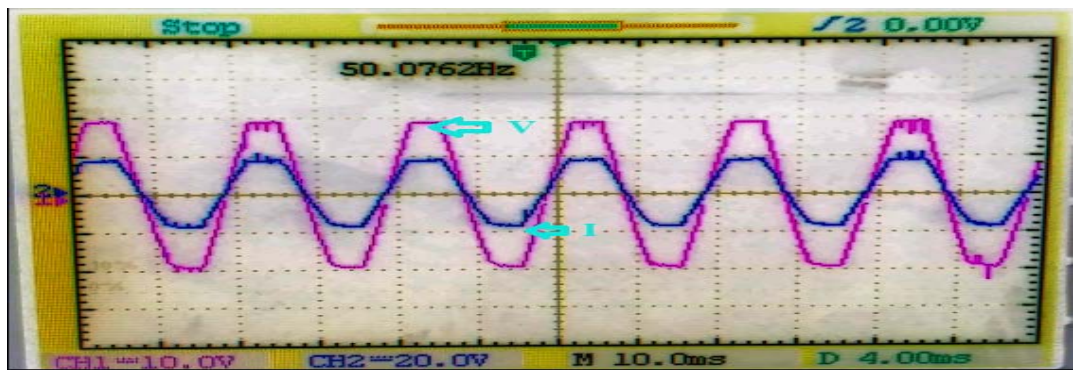

Fig. 21. Input Voltage and Current with Controller.

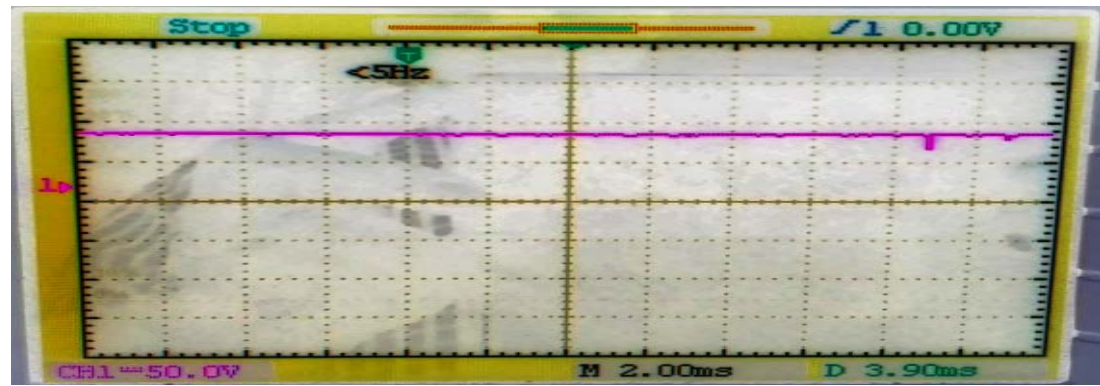

Fig. 22. Output Voltage of SEPIC Converter. 


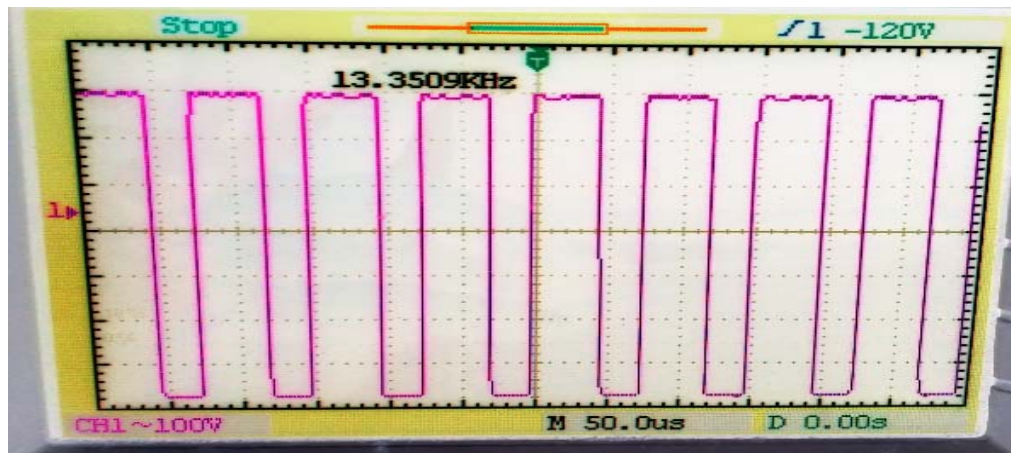

Fig. 23. Output Voltage of Inverter.

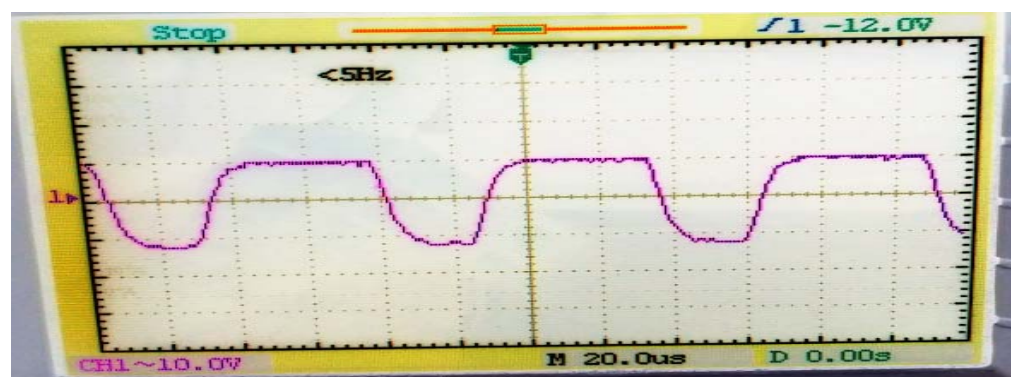

Fig.24. Output Current of Inverter.

Table II. Simulation and Hardware specifications

\begin{tabular}{|l|l|l|}
\hline Description & Simulation & Experimental \\
\hline Inductance(L) & $10 \mu \mathrm{H}$ & $12 \mu \mathrm{H}$ \\
\hline Inductance(L1) & $9 \mu \mathrm{H}$ & $8 \mu \mathrm{H}$ \\
\hline Filter capacitanceC & $1000 \mu \mathrm{F}$ & $1000 \mu \mathrm{F}$ \\
\hline Filter Capacitance(C1) & $104 \mu \mathrm{F}$ & $104 \mu \mathrm{F}$ \\
\hline Filter Capacitance(Co) & $2200 \mu \mathrm{F}$ & $2200 \mu \mathrm{F}$ \\
\hline Load Resistance (Ro) & $3 \Omega$ & $3.5 \Omega$ \\
\hline Load capacitance (C2) & $14 \mu \mathrm{F}$ & $15 \mu \mathrm{F}$ \\
\hline $\begin{array}{l}\text { Load side } \\
\text { Inductance(L2) }\end{array}$ & $50 \mu \mathrm{H}$ & $48 \mu \mathrm{H}$ \\
\hline Input Voltage & $48 \mathrm{~V}$ & $48 \mathrm{~V}$ \\
\hline Switching Frequency & $10 \mathrm{kHz}$ & $10 \mathrm{kHz}$ \\
\hline Output voltage (Vo) & $110 \mathrm{~V}$ & $108 \mathrm{~V}$ \\
\hline Controller IC & FOPID & PIC $16 \mathrm{~F} 84 \mathrm{~A}$ \\
\hline Driver IC & - & IR2110 \\
\hline Diode & 5408 & IN4007 \\
\hline IGBT & $12 \mathrm{FA}-150 \mathrm{~N}$ & $12 \mathrm{FA}-150 \mathrm{~N}$ \\
\hline
\end{tabular}

VII. CONCLUSION

The comparative analysis of SEPIC converter based voltage fed closed loop full bridge series resonant induction heating system with PI \& FOPID control strategies was simulated and the results are presented. Also hardware implementation of the inverter fed induction heating system was done. It can be noticed that the time domain parameters and source current THD has reduced from $4.98 \%$ to $3.73 \%$. Thus the response of FOPID controlled system is superior to the PI controlled system.

The present work deals with comparison of closed loop PI and FOPID controller systems. The closed loop system PR controller will be done in future.

\section{Acknowledgement}

The authors would like to acknowledge the Dr.Sreedevi, HOD/EEE, Dr. S. Hemamalini, Dean (EEE) and Dr. N. Sambandam Vice Chancellor, VIT University Chennai campus for providing the facilities to conduct simulation studies and Hardware. 


\section{Appendix}

PFC-SEPIC PI controller gains: $\mathrm{Kp}=0.06, \mathrm{Ki}=0.9$; PFC- SEPIC FOPID controller gains: $\mathrm{Kp}=0.01, \mathrm{Ki}=0.04$; $\mathrm{Kf}=0.05, \mathrm{Kd}=0.8$.

\section{REFERENCES}

[1] Rahul Pandeyl, Bhim Singh, "Improved Power Quality SEPIC Converter Fed Series Resonant Inverter for Induction Heater", 1st IEEE International Conference on Power Electronics. Intelligent Control and Energy Systems (ICPEICES-2016), pp. 1-6, 2016.

[2] Jesus A, et. al., "Domestic Induction Appliances', IEEE Industry Applications Magazine, vol 16, No. 2, pp.39-47, 2010..

[3] Moreland WC., "The Induction Range: Its Performance and Its Development Problems", IEEE Transactions on Industry Applications, vol. IA-9, No.1, pp-81-85, 1973.

[4] Atsushi F, et. al., "Latest developments of high-frequency series load resonant inverter type built-in cooktops for induction heated all metallic appliances", IEEE 6th International Power Electronics and Motion Control Conference, IPEMC '09. pp. 2537-2544, 2009.

[5] P. Muthu., et. al., "SEPIC Converter for Power Factor Correction in Free Biomass Induction Heating System", Int. Journal of Bio Sciences and Engg, vol 3, No.1, pp. 15-36, 2016.

[6] Lucía O., et. al., "Induction heating technology and its applications: Past developments, current technology, and future challenges" , IEEE Transactions on Industrial Electronics, vol. 61, pp. 2509-2520, 2014.

[7] Esteve V., et. al., "Comparative Study of a Single Inverter Bridge for Dual-Frequency Induction Heating Using Si and SiC MOSFETs", IEEE Transactions on Industrial Electronics, vol. 62, pp. 1440-1450, 2015.

[8] NguyenKL., et. al., "Robustness of a Resonant Controller for a Multiphase Induction Heating System", IEEE Transactions on Industry Applications, vol. 51, no. 1, 2015.

[9] Lucía O., et. al., "Design of home appliances for a DC-based nanogrid system: An induction range study case", IEEE Journal of Emerging and Selected Topics in Power Electronics, on vol. 1, no.4, pp. 315-326, 2013.

[10] Mishima T., et. al., “ A New Current Phasor-Controlled ZVS Twin Half-Bridge High-Frequency Resonant Inverter for Induction Heating”, IEEE Transactions on Industrial Electronics, vol. 61, no.5, pp. 2531-2545, 2014.

[11] Mishima T., et. al., "Bridgeless BHB ZVS-PWM AC-AC Converter for High-Frequency Induction Heating Applications", IEEE Transactions on Industry Applications, vol. 51, No.4, pp. 3304-3315, 2015.

[12] Sarnago $\mathrm{H}$., et. al., "High Efficiency AC-AC Power Electronic Converter Applied to Domestic Induction Heating", IEEE Transactions on Power Electronics, vol. 27, no.8, pp. 3676-3684, 2012.

[13] Sarnago H., et. al., "Efficient and cost-effective ZCS direct ac-ac resonant converter for induction heating", IEEE Transactions on Industrial Electronics, vol. 61, no.5, pp. 2546-2555, 2014.

[14] Park N., et. al., "A Power-Control Scheme With Constant Switching Frequency in Class-D Inverter for Induction-Heating Jar Application", IEEE Transactions on Industrial Electronics, vol. 54, no.3, pp.1252-1260, 2007.

[15] Llorente, S., et. al., "A comparative study of resonant inverter topologies used in induction cookers", Seventeenth Annual IEEE Applied Power Electronics Conference and Exposition, 2002. APEC 2002., vol.2, no.2, pp.1168-1174, 2002.

[16] Cetin S., et. al., "A comparative study of dual half-bridge inverter topologies used in induction cooking", 6th International Conference on Electrical Engineering/Electronics, Computer, Telecommunications and Information Technology, 2009. ECTI-CON 2009.

[17] Molina G., et. al., "Silicon carbide JFET resonant inverter for induction heating home appliances", Proceedings of the 37th Annual Conference of the IEEE Industrial Electronics Society (IECON), vol. 1 pp. 2551-2556, 2011.

[18] Avellaned J., et. al., "Half-bridge resonant inverter with SiC cascode applied to domestic induction heating", Twenty-Eighth Annual IEEE Applied Power Electronics Conference and Exposition (APEC), pp.122-127, 2013.

[19] Saoudi, M., et. al., "Induction cooking systems with single switch inverter using new driving techniques", IEEE International Symposium Industrial Electronics (ISIE), pp.878-883, 2010.

[20] Acero J., et. al., "Frequency-dependent resistance in litz-wire planar windings for domestic induction heating appliances", IEEE Trans. Power Electron., vol. 21, no. 4, pp. 856-866, 2006.

[21] Lucía JO., et. al., "Configurable snubber network for efficiency optimization of resonant converters applied to multi-load induction heating”, Electronics Letters, vol. 47,nNo.17, pp. 989-991, 2011.

[22] Santhi Mary Antony A, et. al., " Performance comparison of llcc resonant based multi output converter and single inductor boost based multi output converter for led driver applications", International Journal of Engineering and Technology (IJET)Vol 8 No 5 OctNov 2016.

[23] Vanitha D, M. Rathinakumar., et. al., "Photovoltaic based hysteretic controlled buck boost converter with coupled inductor", International Journal of Engineering and Technology (IJET), Vol 9 No 4 Aug-Sep 2017.

[24] Vanitha D, M. Rathinakumar., et. al., "Fractional Order PID Controlled PV Buck Boost Converter with Coupled Inductor", International Journal of Power Electronics and Drive System (IJPEDS) Vol. 8, No. 3, September 2017, pp. 1401 1407

[25] Paranthagan B.,, et. al., "Comparative Analysis of Performance of the SEPIC Converter Using PID and Fuzzy Logic Controllers for LED Lighting Applications., International Journal of Emerging Technology in Computer Science \& Electronics(IJETCSE) ISSN: 0976-1353 Volume 12 Issue 2 -JANUARY 2015.

\section{BIOGRAPHIES OF AUTHORS}

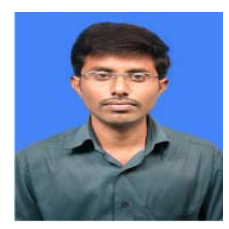

P.MUTHU received the B.E. degree in Electrical and Electronics engineering from Dhanalakshmi engineering college Anna University, Chennai, in 2007, and the M.Tech degree in Applied electronics from the Department of Electrical and electronics Engineering, Adhiparasakthi Engineering college Anna University, in 2010. He is currently doing PHD in VIT Chennai campus.

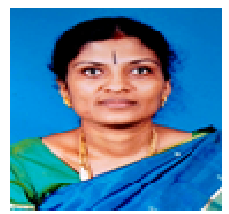

DR.C.UMAYALCHANDRAHASAN has obtained her ME degree from Anna University, Tamil Nadu, India, in the year 2005. She has 12 years of teaching experience and 8 years of Industrial experience. She completed her PhD at ANNA University, Chennai in 2014. She is currently working as Associate Professor in the Department of EEE at VIT University, Chennai. 